\title{
E-cadherin and NEDD9 expression in primary colorectal cancer, metastatic lymph nodes and liver metastases
}

\author{
PETRA JURČIĆ ${ }^{1}$, PETRA RADULOVIĆ ${ }^{2}$, MELITA PERIĆ BALJA ${ }^{3}$, MILAN MILOŠEVIĆ ${ }^{4}$ and BOŽO KRUŠLIN ${ }^{2,5}$ \\ ${ }^{1}$ Department of Radiotherapy and Medical Oncology, University Hospital for Tumors; \\ ${ }^{2}$ Ljudevit Jurak Department of Pathology and Cytology; ${ }^{3}$ Department of Oncological Pathology, \\ University Hospital for Tumors, Clinical Hospital Center Sestre Milosrdnice; ${ }^{4}$ Department for \\ Environmental and Occupational Health, University of Zagreb, School of Medicine, \\ Andrija Štampar School of Public Health; ${ }^{5}$ School of Medicine, University of Zagreb, Zagreb 10000, Croatia
}

Received November 18, 2017; Accepted December 21, 2018

DOI: $10.3892 / \mathrm{ol} .2019 .9917$

\begin{abstract}
In Croatia, colorectal cancer mortality rates in males are the third highest in Europe, after Hungary and Slovakia. The results for females rank Croatia in second place after Hungary. According to previous studies, the loss of E-cadherin expression and the higher expression of neural precursor cell-expressed developmentally downregulated 9 (NEDD9) are associated with a worse prognosis. The aim of the present study was to analyze the immunohistochemical expression of NEDD9 and E-cadherin as markers of metastatic potential using a tissue microarray. This retrospective study included 40 previously untreated patients, including 23 males and 17 females with a median age of 64.5 years (range 38-84), with colorectal cancer and synchronous liver metastases that underwent simultaneous colorectal and hepatic resection between January 1st 2006 and December 31st 2013, in the Clinical Hospital Center Sestre Milosrdnice (Zagreb, Croatia). The most frequent tumor stage was T3, while the most frequent nodal stage was N1. Microvascular invasion was present in $37.5 \%$ of patients, while perineural invasion was observed in $30 \%$ of patients. The immunohistochemical staining index of E-cadherin was highly positive in $87.5 \%$ samples of colorectal cancer, $67.7 \%$ of lymph nodes and $77.5 \%$ of liver metastases. In the primary tumor, highly positive NEDD9 expression was identified in $22.5 \%$ of patients. In lymph nodes, it was identified in $35.5 \%$ of patients, while in the liver, it was identified in $30 \%$ of patients. Significant positive correlations were observed between the percentage of positive lymph nodes and the immunohistochemical staining index of E-cadherin
\end{abstract}

Correspondence to: Dr Petra Jurčić, Department of Radiotherapy and Medical Oncology, University Hospital for Tumors, Clinical Hospital Center Sestre Milosrdnice, Ilica 197, Zagreb 10000, Croatia E-mail: petra.jurcic@gmail.com

Key words: E-cadherin, neural precursor cell-expressed developmentally downregulated 9 , colorectal cancer, liver metastases, immunohistochemistry, survival
( $\rho=0.372 ; P=0.039)$ and NEDD9 $(\rho=0.451 ; P=0.011)$ in lymph nodes. After the conclusion of the study, $55 \%$ of the patients succumbed. No significant differences in survival rates were identified regarding the expression of E-cadherin and NEDD9 in the primary tumor, metastatic lymph nodes and liver metastases. Due to the small sample size and the negative results obtained, further research is required to implement these parameters as prognostic factors.

\section{Introduction}

Colorectal cancer (CRC) is the second most frequently diagnosed cancer and the third leading cause of cancer-related death in Croatia. According to the data obtained from the Croatian National Cancer Registry for 2015, there were 1,890 new cases in the male population, and 1,339 in the female population. During the same year, 2,056 people succumbed to CRC (1). Despite the existence of the Croatian national colorectal screening program, the trends in the rates of incidence and mortality still display an increase in CRC. At the time of primary diagnosis, $41 \%$ of patients have positive regional lymph nodes (LN) and $14 \%$ of patients have evidence of distant metastases (1).

Approximately $75-80 \%$ of all CRC cases are sporadic, while approximately $20 \%$ may be familial, due to low-penetrance genes without a clear pattern. Only 5\% of CRCs are clearly inherited (familial adenomatous polyposis, Lynch syndrome, MUTYH-associated polyposis, Peutz-Jeghers syndrome, juvenile polyposis, Cowden syndrome and serrated polyposis). Most cases of hereditary CRC have an autosomal dominant inheritance pattern (except MUTYH-associated polyposis) (2). Relevant risk factors are as follows: Age ( $>50$ years), lifestyle (high-fat, low-fiber-diet, obesity, physical inactivity, smoking and alcohol consumption), colorectal adenoma, inflammatory bowel disease (Crohn's disease and ulcerative colitis), and a family history of CRC. Primary tumor location is an important prognostic factor and has an effect on clinical presentation. The initial symptoms of left-sided CRC tumors are a change in bowel habits and bleeding; as these symptoms are more palpable, therefore they are identified, and CRC is diagnosed, at an earlier stage. Right-sided CRC tumors grow unnoticed 
until they are large, and symptoms are unspecific: Abdominal pain, vomiting and anemia.

Diagnosisshouldbeconfirmed with an endoscopically-guided biopsy. Diagnostic workup should include a complete blood count, liver and renal function tests, carcinoembryonic antigen and cancer antigen 19-9, multi-slice computed tomography of the chest, abdomen and pelvis, and magnetic resonance imaging of the pelvis (for rectal cancer). A multidisciplinary team approach insures that patients receive the best possible care. The pathology report should include the histology type, degree of differentiation, depth of bowel wall infiltration (T status), affected and examined LNs (N status) and presence of lymphovascular or perineural invasion (PNI). Clinical and pathological staging should be performed according to the latest edition of the International Union Against Cancer (UICC)/American Joint Committee of Cancer (AJCC) tumor-node-metastasis (TNM) classification for CRC. Clinical outcomes have improved dramatically over the past 15 years due to the availability of more active chemotherapeutic agents, and anti-VEGF and anti-EGFR targeted agents, but also due to the development of different surgical approaches (including colon-first, liver-first, two-step or simultaneous resection) and the possibilities for the local ablative treatment of liver, lung and peritoneal metastases (including chemoembolization, radioembolization, stereotactic radiotherapy and radiofrequency ablation). The median survival rate for patients with metastatic $\mathrm{CRC}$ is currently about 30 months. This improvement is achieved due to continuum of care, which includes different possible combinations of patient treatment i.e., combinations of drugs and different time-frame of therapy. The latest findings are focused on microsatellite instability high $\mathrm{CRC}$, which may be sensitive to programmed cell death protein 1 (PD-1) inhibitors.

It is critical to identify the molecular markers of CRC, which can be used to monitor or predict the progression and prognosis of patients with CRC, and to investigate these potential biomarkers as therapeutic targets.

A crucial role in the progression and aggressiveness of CRC is attributed to epithelial-mesenchymal transition (EMT), a reversible developmental process that includes the dissolution of adherens junctions and loss of apicobasolateral polarity, resulting in the formation of migratory mesenchymal cells with invasive properties. During the EMT process, cancer cells lose the expression of cellular adhesion proteins such as epithelial (E-) cadherin and $\gamma$-catenin (3). E-cadherin is a member of the large cadherins family of calcium-dependent cell adhesion proteins. This single-pass transmembrane glycoprotein, encoded by the CDH1 gene on chromosome 16q22.1, has a molecular weight of $120 \mathrm{kDa}$. The mature protein comprises a long extracellular domain with five E-cadherin repeats (EC1-5), a short transmembrane domain, and a cytoplasmic domain that includes juxtamembranous p120, and $\gamma$ - and $\beta$-catenin binding sites (4).

Predominantly expressed at the basolateral membrane of epithelial cells, where its function is primarily cell-cell adhesion, E-cadherin has been shown to be essential during morula compaction and the subsequent epithelial tissue organization, which is achieved through hemophilic interactions between cadherin molecules, first among adjacent cells (trans-interaction) and then within the same cell by lateral association (cis-interaction) (5). Malignant epithelial cells undermine the function of E-cadherin in several ways, including gene mutations, epigenetic silencing by promoter hypermethylation, loss of heterozygosity, transcriptional silencing and microRNAs that regulate expression, transport and protein turnover at the cell surface (6-8).

Neural precursor cell-expressed developmentally downregulated 9 (NEDD9) protein is a member of the non-catalytic scaffolding proteins family (9), which also includes CASS1/BCAR1/p130Cas, CASS3/EFS/Sin and CASS4/HEPL. These proteins show the conservation of similar domain structures; an N-terminal Src homology 3 (SH3) domain that binds protein substrates (e.g., FAK, PYK2) and contains polyproline motifs, and a large substrate domain incorporating multiple YxxP motifs, which are phosphorylated by the Src family kinases to create binding sites for proteins with $\mathrm{SH} 2$ domains. The serine-rich region likely folds into a 4-helix bundle and highly conserved carboxyl-terminal domain that mediates homo- and heterodimerization with CASS1/BCAR1/p130Cas. Although the protein is mainly cytoplasmic, small quantities are localized with centrosomes and the ciliary basal body. The signaling function of NEDD9 is integrin-dependent, regulated by the phosphorylation of serines, threonines and tyrosines in the structural domains. PP2A phosphatases are potential regulators of the NEDD9 phosphorylation status. NEDD9 has a molecular weight of $93 \mathrm{kDa}$ and oscillates between a faster migrating form of $105 \mathrm{kDa}$ in $\mathrm{G} 1 / \mathrm{S}$ cells and a slower migrating form of $115 \mathrm{kDa}$ in G2/M cells. Previous studies have identified the crucial role of NEDD9 in the coordination of signaling cascades, contributing to changes in cell adhesion, migration, invasion and EMT $(9,10)$. In normal human tissue, the highest level of NEDD9 is expressed in the lungs and kidneys, which are rich in immature lymphoid cells, and in the fetal brain prior to downregulation in the adult brain (10). Many cell lines, such as epithelial tumor-, melanoma-, lymphomaand glioblastoma-derived cell lines, express an abundance of NEDD9.

Due to its pleotropic functions (cell adhesion, migration, invasion and EMT), the elevated expression of NEDD9 has emerged as a predictor of poor outcome, metastatic potential and chemoresistence in multiple cancer types (breast cancer, gastric cancer, glioblastoma, head and neck squamous cell carcinoma, hepatocellular carcinoma, non-small cell lung cancer, ovarian cancer, renal cancer, pancreatic ductal adenocarcinoma, prostate cancer and T-cell leukemia) (10-19). NEDD9 is a bona fide melanoma metastasis gene that enhances invasion in vitro and metastasis in vivo of both normal and transformed melanocytes (14). A growing body of preclinical data supports the theory that altered NEDD9 function is associated with other human diseases, such as stroke, Alzheimer's disease and autosomal dominant polycystic kidney disease.

The data regarding NEDD9 and E-cadherin expression in CRC are insufficient. However, a study has shown that overexpression of NEDD9 positively mediates the canonical Wnt/ß-catenin signaling pathway in CRC and it also negatively regulates membrane expression of E-cadherin (3). There is also a paper in which NEDD9 is identified as differentially expressed gene, associated with cyclin D1, which can be a molecular target for the treatment of CRC, because it interacts with their corresponding anti-neoplastic drugs (20). Therefore, our study aimed to analyze the immunohistochemical 
NEDD9 and E-cadherin expression in a tissue microarray of nonmetastatic and metastatic CRC, and to determine whether their expression is associated with the clinical behavior and prognosis of CRCs.

\section{Patients and methods}

Patient information. Following approval by the Ethical Committee of Clinical Hospital Center Sestre Milosrdnice (Zagreb, Croatia), a total of 40 pairs of formalin-fixed, paraffin-embedded (FFPE) primary CRC and corresponding matched liver metastasis tissue specimens were retrieved from the tissue bank of the Ljudevit Jurak Department of Pathology and Cytology. The patients gave their written informed consent for the use of their biological materials and data in research. The patients had no history of the familial aggregation of $\mathrm{CRC}$, had not been previously treated with chemo- or/and radiotherapy, and had undergone simultaneous colorectal and hepatic resection between January 1st, 2006 and December 31st, 2013. Tumor staging was performed according to the 7th edition of the TNM classification for CRC. The follow up deadline was December 31st, 2015. The survival time was calculated from the date of surgery to the follow up deadline, or the date of death. The clinicopathological features of patients are summarized in Table I.

Immunohistochemistry. Immunohistochemical analyses were performed by two board-certified pathologists who were blinded to the clinical data of the patients. Paraffin-embedded tissue sections (thickness 3-5 $\mu \mathrm{m}$ ) were deparaffinized for $2 \mathrm{~h}$ at $60^{\circ} \mathrm{C}$ and then washed with distilled water after two and three changes of xylene and ethanol, respectively. Immunohistochemical staining was performed using the microwave streptavidin immunoperoxidase (MSIP) protocol, and by use of the labelled streptavidin-biotin (LSAB) method on a TechMate ${ }^{\mathrm{TM}}$ Horizon automated immunostainer (Dako; Agilent Technologies, Inc., Santa Clara, CA, USA) (11). Sections were incubated with rabbit anti-human NEDD9 polyclonal (dilution 1:100, cat. no. ab37161; Abcam, Cambridge, UK) and mouse anti-human E-cadherin monoclonal (dilution 1:50, clone NCH-38; Dako; Agilent Technologies, Inc.) antibodies overnight at $4^{\circ} \mathrm{C}$, followed by incubation with horseradish peroxidase-conjugated secondary goat anti-rabbit antibody (Abcam) for $1 \mathrm{~h}$ at room temperature. Sections were then washed with PBS and the antigen-antibody complex was visualized.

The reactions were determined in epithelial tumor components, as well as from the epithelial components of metastatic tumors in the LN and liver (Fig. 1). Positive reactions were determined at the site of strongest activity ('hot spot') under a magnification, $\mathrm{x} 400$ for a total of 1,000 tumor cells. The 'hot spot' was established following inspection of the whole section at a magnification of $\mathrm{x} 40$. The results for E-cadherin were presented semi-quantitatively using an immunohistochemical staining index (ISI), obtained by multiplying the intensity of reaction with the percentage of cells with a positive reaction. The range of ISI was from 0 to 9: 0, represents no reaction, 1-4 represents a low E-cadherin reaction, 5-9 represents a high E-cadherin reaction. The intensity of the reaction was scored as follows: 0 , no reaction; 1 , weak reaction; 2 , moderate
Table I. Clinical description of the investigated sample (Dukes D, total $n=40$ ).

\begin{tabular}{|c|c|c|}
\hline Parameter & $\mathrm{n}$ & $\%$ \\
\hline \multicolumn{3}{|l|}{ Sex } \\
\hline Male & 23 & 57.5 \\
\hline Female & 17 & 42.5 \\
\hline \multicolumn{3}{|c|}{ Localization of primary tumor } \\
\hline Colon & 28 & 70.0 \\
\hline Rectosigmoid junction & 2 & 5.0 \\
\hline Rectum & 10 & 25.0 \\
\hline \multicolumn{3}{|l|}{ T status } \\
\hline $\mathrm{T} 1$ & 0 & 0 \\
\hline $\mathrm{T} 2$ & 3 & 7.5 \\
\hline $\mathrm{T} 3$ & 34 & 85.0 \\
\hline $\mathrm{T} 4$ & 3 & 7.5 \\
\hline \multicolumn{3}{|l|}{$\mathrm{N}$ status } \\
\hline N0 or Nx & 9 & 22.5 \\
\hline N1 & 18 & 45.0 \\
\hline $\mathrm{N} 2$ & 13 & 32.5 \\
\hline \multicolumn{3}{|l|}{ Surgical margins } \\
\hline Negative & 39 & 97.5 \\
\hline Positive & 1 & 2.5 \\
\hline \multicolumn{3}{|l|}{ Microvascular invasion } \\
\hline Absent & 25 & 62.5 \\
\hline Present & 15 & 37.5 \\
\hline \multicolumn{3}{|l|}{ Perineural invasion } \\
\hline Absent & 28 & 70.0 \\
\hline Present & 12 & 30.0 \\
\hline \multicolumn{3}{|l|}{ Outcome } \\
\hline Survived & 18 & 45.0 \\
\hline Succumbed & 22 & 55.0 \\
\hline
\end{tabular}

T, tumor; $\mathrm{N}$, lymph node.

reaction; and 3, strong reaction. The percentage of immunoreactive tumor cells was scored as follows: 0 , for no reaction; $1,0-10 \%$ of positive tumor cells; $2,>10-50 \%$ of positive tumor cells; and $3,>50 \%$ of positive tumor cells (21). The results for NEDD9 were presented semi-quantitatively and scored in the following way: 0 , no reaction; 1 , weak reaction in $0-10 \%$ of tumor cells; 2 , moderate reaction in $>10-25 \%$ of tumor cells; and 3 , strong reaction in $>25 \%$ of tumor cells (11).

Statistical analysis. The normality of data distribution was assessed with the Kolmogorov-Smirnov test, and appropriate non-parametric tests were used in the following statistical analyses. Spearman's $\rho$ and Kendal's $\tau$-b correlation coefficients for nominal-ordinal correlation were used to analyze associations between E-cadherin and NEDD9 expression in the primary tumor, LN and liver with other clinical variables. A log-rank (Mantel-Cox) test of the equality of survival distributions was performed for the expression of E-cadherin and NEDD9 in the primary tumor, LN and liver in relation 

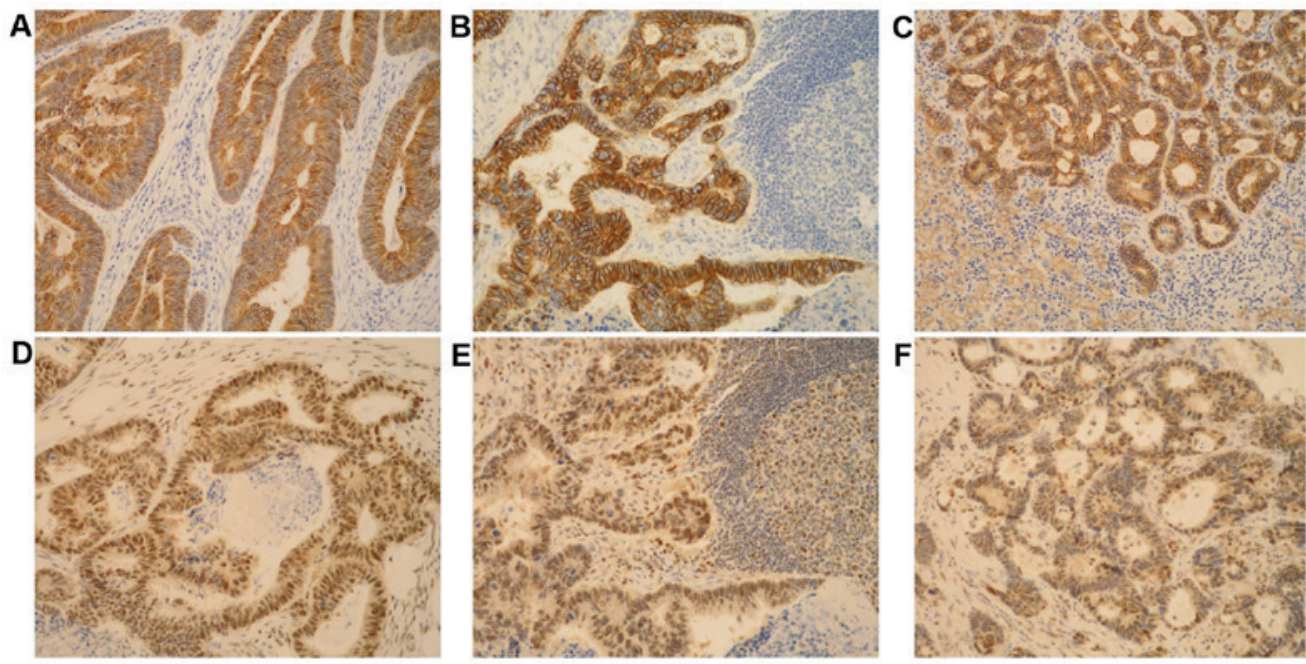

Figure 1. High intensity immunohistochemical expression of E-cadherin in (A) the primary tumor, (B) LN metastasis and (C) liver metastasis. High intensity immunohistochemical expression of neuronal precursor cell-expressed developmentally downregulated 9 in (D) the primary tumor, (E) LN metastasis and (F) liver metastasis. Magnification, x200. LN, lymph node; E-cadherin, epithelial cadherin.

to the survival outcome. The outcomes were illustrated with Kaplan-Meier survival curves. $\mathrm{P}<0.05$ was considered to indicate a statistically significant difference. The data analysis software SPSS Statistics, version 23.0 (IBM Corp., Armonk, NY, USA) was used for statistical analyses and the production of graphical images.

\section{Results}

A clinical description of the investigated sample is shown in Table I. Of the patients, $57.5 \%$ were male. Median (interquartile range, IQR) age was 64.0 (57.3-73.5) years. Of the tumors, $70.0 \%$ were localized in the right colon. Median (IQR) tumor size was 50.0 (36.3-60.0) $\mathrm{mm}$. Among the patients, $85.0 \%$ had T3 stage, and $22.5 \%$ had N0 or Nx stage. Microvascular invasion was positive in $37.5 \%$ of patients, and PNI in $30.0 \%$ of patients. Death occurred in $55.0 \%$ of patients, with a median (IQR) survival time of 620.5 (164.3-964.8) days. The median (IQR) percentage of positive $\mathrm{LN}$ was $13.9 \%$ (0.0-44.1\%).

The E-cadherin and NEDD9 expression scores in the investigated samples are shown in Table II. $87.5 \%$ of the patients had a strong expression of E-cadherin in the primary tumor, $67.7 \%$ in the LN, and $77.5 \%$ in the liver. Highly positive NEDD9 expression in the primary tumor was identified in $22.5 \%$ of patients, while $35.5 \%$ had highly positive NEDD9 expression in the $\mathrm{LN}$, and $30.0 \%$ in the liver.

The correlation coefficients for E-cadherin and NEDD9 expression in the primary tumor, LN and liver with clinical characteristics are shown in Table III. Significant positive correlation was noted between the percentage of positive LN with the ISI for E-cadherin in the $\mathrm{LN}(\rho=0.372 ; \mathrm{P}=0.039)$ and with NEDD9 expression in $\mathrm{LN}(\rho=0.451 ; \mathrm{P}=0.011)$, indicating that higher expression is significantly associated with a higher percentage of positive LN. Kaplan-Meier survival curves with log-rank tests for the expression of E-cadherin and NEDD9 in the primary tumor, $\mathrm{LN}$ and liver in relation to the survival outcome are shown in Fig. 2. There was no significant prediction of mortality associated with the expression of E-cadherin and NEDD9 at any location, indicating that for this tumor stage (Dukes D), other prognostic markers are likely to be more clinically relevant.

\section{Discussion}

Left- and right-sided CRCs differ with respect to biology, epidemiology, pathology and clinical presentation. It is expected that most patients with synchronous liver metastases have right-sided CRC.

Various studies have shown controversial results regarding the expression levels of E-cadherin in CRC. Yun et al (22) studied stage III CRC, and found positive expression in $98.3 \%$ of samples. Dorudi et al (23) found that $81.2 \%$ of well and moderately differentiated tumors expressed strong positivity for E-cadherin, while $85.7 \%$ of poorly differentiated tumors were E-cadherin-negative. Three studies (Miladi-Abdennadher et al (24), Palaghia et al (25) and Elzagheid et al (26) identified a marginally lower expression (74.3, 67.69 and 59\%, respectively). We attribute the results of Elzagheid et al (26) to the inclusion of all CRC stages in their study. In contrast to the aforementioned studies, Gu et al (27) identified that only $20 \%$ of patients with metastatic CRC had positive E-cadherin expression. The limitation of our study is reflected in the fact that we assessed only the membranous expression of E-cadherin. Elzagheid et al (28) assessed the cytoplasmic expression of E-cadherin. Tóth et al (29) used a scale based only on the percentage of immunopositive cells. Palaghia et al (25) used two scoring systems that were initially established for gastric carcinoma.

Our results show concordance with the results of Elzagheid et al (26), Khoursheed et al (30) and Roca et al (31), who reported that E-cadherin expression was not associated with tumor stage. Nevertheless, Ghadimi et al (32) reported a significant association between reduced E-cadherin and lower tumor grade, but did not identify a clear correlation between the loss of E-cadherin expression and the depth of tumor infiltration into the intestinal wall. Kwak et al (33) showed that the reduced expression of E-cadherin was associated with advanced stage tumors $(\mathrm{P}=0.029)$, while Lugli et al (34) 
Table II. E-cadherin and NEDD9 expression in the investigated sample (Dukes D, total $n=40$ ).

\begin{tabular}{lll} 
ISI & $\mathrm{n}$ & $\%$ \\
\hline
\end{tabular}

E-cadherin in primary tumor

0

1

2

2

E-cadherin in lymph nodes

0

4

1

2

E-cadherin in liver

0
1
2

NEDD9 in primary tumor

0
1
2
3

NEDD9 in lymph nodes

\begin{tabular}{lrr}
0 & 7 & 22.6 \\
1 & 5 & 16.1 \\
2 & 8 & 25.8 \\
3 & 11 & 35.5 \\
NEDD9 in liver & & \\
0 & 3 & 7.5 \\
1 & 11 & 27.5 \\
2 & 14 & 35.0 \\
3 & 12 & 30.0 \\
\hline
\end{tabular}

ISI, immunohistochemical staining index; NEDD9, neuronal precursor cell expressed developmentally downregulated 9 .

demonstrated that the loss of membranous E-cadherin was associated with a higher $\mathrm{T}$-stage $(\mathrm{P}=0.03)$. Similar results were reported by Miladi-Abdennadher et al (24), who reported that E-cadherin expression was correlated with tumor size $(\mathrm{P}=0.02)$. Although the stage of the tumor was determined for every patient, the relatively small size of the group represented a limitation of the afore-mentioned study.

However, Roca et al (31) found no association between E-cadherin expression and LN metastasis. Similar to the present study, Kwak et al (33) demonstrated an association between E-cadherin expression and $\mathrm{LN}$ metastasis $(\mathrm{P}=0.004)$. Lugli et al (34) reported that in mismatch repair-proficient $\mathrm{CRC}$, the loss of membranous E-cadherin was independently associated with a higher $\mathrm{N}$ stage $(\mathrm{P}<0.0001)$. In MLH1 $\mathrm{CRC}$, the loss of membranous E-cadherin was associated with a higher $\mathrm{N}$ stage $(\mathrm{P}=0.05)(34)$. Node-positive cancers exhibited significant loss of E-cadherin $(\mathrm{P}<0.001)$ according to Karamitopoulou et al (35). Ozgüven et al (36) found that reduced E-cadherin expression was significantly associated with $\mathrm{LN}$ metastasis $(\mathrm{P}=0.01)$. A borderline association of
E-cadherin expression and $\mathrm{LN}$ metastasis $(\mathrm{P}=0.09)$ was reported by Elzagheid et al (26). Kim et al (37) reported that E-cadherin expression may serve as a predictive marker for tumor invasion and LN metastasis.

E-cadherin expression was increased in up to $40 \%$ of liver metastases, compared with only $17 \%$ of metastatic LNs that were studied by Ikeguchi et al (38), whose results are consistent with those of the present study. The results of Kim et al (39), who analyzed patients that had undergone curative surgery for primary CRC and liver metastases, showed that E-cadherin expression in the tumor center was greater than that of the tumor margin, in the primary tumor and liver metastases $(\mathrm{P}<0.001, \mathrm{P}=0.006$, respectively). A likely explanation is the possibility that tumor cells regain epithelial features in distant metastases. Dorudi et al (23) and Mohri (40) postulated that negative E-cadherin expression was associated with liver metastasis. Nanashima et al (41) reported that negative E-cadherin expression tended to be associated with a poor prognosis. Kaihara et al (42) reported that LN metastasis and the decreased expression of E-cadherin were associated with liver metastasis. Elzagheid et al (28) reported that the E-cadherin membranous (MI) and cytoplasmic index (CI) were significantly higher in liver metastases compared to other anatomic sites (MI, $\mathrm{P}=0.034$; $\mathrm{CI}, \mathrm{P}=0.022$ ). Truant et al (43) demonstrated that the expression of E-cadherin significantly increased in metastases compared with normal liver tissue. Gagliardi et al (44) compared liver metastases with their corresponding primary tumors, and found a complete loss of E-cadherin expression in $50 \%$ of liver metastases, while $86 \%$ of the primary tumors associated with the liver metastases exhibited strong expression.

A connection between survival rate and the reduced expression of E-cadherin was found by Kwak et al (33) and Kang et al (45), but was without statistical significance in a multivariate analysis; Lee et al (46) identified that the aberrant expression of E-cadherin in the invasive margin was a significant and independent risk factor for disease-free and overall survival in multivariate analysis, while Yun et al (22) reported that decreasing E-cadherin expression was associated with a poor outcome in terms of overall survival in univariate $(\mathrm{P}=0.016)$, but not multivariate $(\mathrm{P}=0.303$, risk ratio $=1.984$, $95 \%$ confidence interval $=0.539-7.296)$, analysis (46). The present study did not identify any statistically significant association between the survival rate and E-cadherin expression. Regarding the controversial results of E-cadherin expression, it should be noted that in various papers that we have mentioned, the research procedures were performed using various monoclonal antibodies, devices (instruments), classifications, and scoring systems (cut-off values). Therefore, there are many points that could have affected the difference in the results.

Studies of the immunohistochemical expression of NEDD9 in human tissue samples are few in the literature. Xia et al (47) found that NEDD9 expression is increased in $~ 50 \%$ of CRC samples, compared with normal colorectal tissue. Li et al (48) noted the high expression of NEDD9 in 68 of 92 CRC samples, compared with 12 of 92 in normal tissues $(\mathrm{P}<0.01)$. It was found that NEDD9 was significantly associated with an advanced TNM stage $(\mathrm{P}=0.014)$, $\mathrm{pT}$ grade $(\mathrm{P}=0.009), \mathrm{pN}(\mathrm{P}=0.013)$ and pM status $(\mathrm{P}=0.047)$. Patients with a higher NEDD9 expression had a significantly shorter overall survival rate $(\mathrm{P}<0.01)(48)$. 
Table III. Coefficients for the correlation between E-cadherin and NEDD9 expression in the primary tumor, lymph nodes and liver with clinical characteristics.

\begin{tabular}{|c|c|c|c|c|c|c|}
\hline \multirow[b]{2}{*}{ Expression of site } & \multicolumn{3}{|c|}{ E-cadherin } & \multicolumn{3}{|c|}{ NEDD9 } \\
\hline & Primary tumor & Lymph nodes & Liver & Primary tumor & Lymph nodes & Liver \\
\hline \multicolumn{7}{|l|}{ Age (years) } \\
\hline$\rho$ & 0.245 & -0.048 & 0.305 & -0.084 & -0.139 & 0.052 \\
\hline $\mathrm{P}$ & 0.127 & 0.799 & 0.055 & 0.605 & 0.457 & 0.748 \\
\hline $\mathrm{n}$ & 40 & 31 & 40 & 40 & 31 & 40 \\
\hline \multicolumn{7}{|l|}{ Tumor size $(\mathrm{cm})$} \\
\hline$\rho$ & -0.166 & -0.281 & -0.265 & -0.025 & 0.08 & 0.175 \\
\hline $\mathrm{P}$ & 0.305 & 0.126 & 0.098 & 0.88 & 0.669 & 0.281 \\
\hline $\mathrm{n}$ & 40 & 31 & 40 & 40 & 31 & 40 \\
\hline \multicolumn{7}{|l|}{$\mathrm{T}$ status } \\
\hline$\rho$ & & -0.191 & & & 0.047 & 0.299 \\
\hline $\mathrm{P}$ & & 0.304 & & & 0.803 & 0.061 \\
\hline $\mathrm{n}$ & 40 & 31 & 40 & 40 & 31 & 40 \\
\hline \multicolumn{7}{|l|}{$\mathrm{N}$ status } \\
\hline$\rho$ & 0.263 & 0.345 & 0.084 & 0.106 & 0.261 & 0.195 \\
\hline $\mathrm{P}$ & 0.102 & 0.057 & 0.604 & 0.515 & 0.156 & 0.227 \\
\hline $\mathrm{n}$ & 40 & 31 & 40 & 40 & 31 & 40 \\
\hline \multicolumn{7}{|l|}{ M status } \\
\hline \multicolumn{7}{|l|}{$\rho$} \\
\hline \multicolumn{7}{|l|}{$\mathrm{P}$} \\
\hline $\mathrm{n}$ & 40 & 31 & 40 & 40 & 31 & 40 \\
\hline \multicolumn{7}{|l|}{ Surgical margins } \\
\hline$\tau \mathrm{B}$ & 0.06 & -0.334 & 0.086 & -0.108 & -0.255 & 0.015 \\
\hline $\mathrm{P}$ & 0.711 & 0.066 & 0.598 & 0.507 & 0.166 & 0.929 \\
\hline $\mathrm{n}$ & 40 & 31 & 40 & 40 & 31 & 40 \\
\hline \multicolumn{7}{|c|}{ Microvascular invasion } \\
\hline$\rho$ & 0.292 & -0.022 & 0.176 & -0.053 & -0.041 & 0.108 \\
\hline $\mathrm{P}$ & 0.067 & 0.907 & 0.278 & 0.743 & 0.825 & 0.508 \\
\hline $\mathrm{n}$ & 40 & 31 & 40 & 40 & 31 & 40 \\
\hline \multicolumn{7}{|l|}{ Perineural invasion } \\
\hline$\rho$ & 0.07 & 0.041 & 0.225 & 0.039 & 0.192 & -0.094 \\
\hline $\mathrm{P}$ & 0.668 & 0.826 & 0.163 & 0.81 & 0.3 & 0.563 \\
\hline $\mathrm{n}$ & 40 & 31 & 40 & 40 & 31 & 40 \\
\hline \multicolumn{7}{|c|}{ Positive lymph nodes (\%) } \\
\hline$\rho$ & 0.2 & 0.372 & -0.016 & 0.026 & 0.451 & 0.175 \\
\hline $\mathrm{P}$ & 0.217 & $0.039^{\mathrm{a}}$ & 0.922 & 0.872 & $0.011^{\mathrm{a}}$ & 0.281 \\
\hline $\mathrm{n}$ & 40 & 31 & 40 & 40 & 31 & 40 \\
\hline \multicolumn{7}{|l|}{ Sex } \\
\hline$\tau \mathrm{B}$ & 0.177 & 0.249 & 0.107 & 0.129 & 0.207 & 0.217 \\
\hline $\mathrm{P}$ & 0.263 & 0.157 & 0.497 & 0.378 & 0.217 & 0.143 \\
\hline $\mathrm{n}$ & 40 & 31 & 40 & 40 & 31 & 40 \\
\hline \multicolumn{7}{|l|}{ Survival time (days) } \\
\hline$\rho$ & -0.137 & -0.075 & -0.292 & -0.035 & -0.229 & 0.068 \\
\hline $\mathrm{P}$ & 0.398 & 0.688 & 0.067 & 0.829 & 0.215 & 0.676 \\
\hline $\mathrm{n}$ & 40 & 31 & 40 & 40 & 31 & 40 \\
\hline
\end{tabular}

${ }^{a} \mathrm{P}<0.05$. ISI, immunohistochemical staining index; T, tumor; $\mathrm{N}$, lymph node; NEDD9, neuronal precursor cell expressed developmentally downregulated 9; M, metastasis; $\rho$, Spearman's rank correlation coefficient; $\tau$ B, Kendall's $\tau$-b correlation coefficient. 

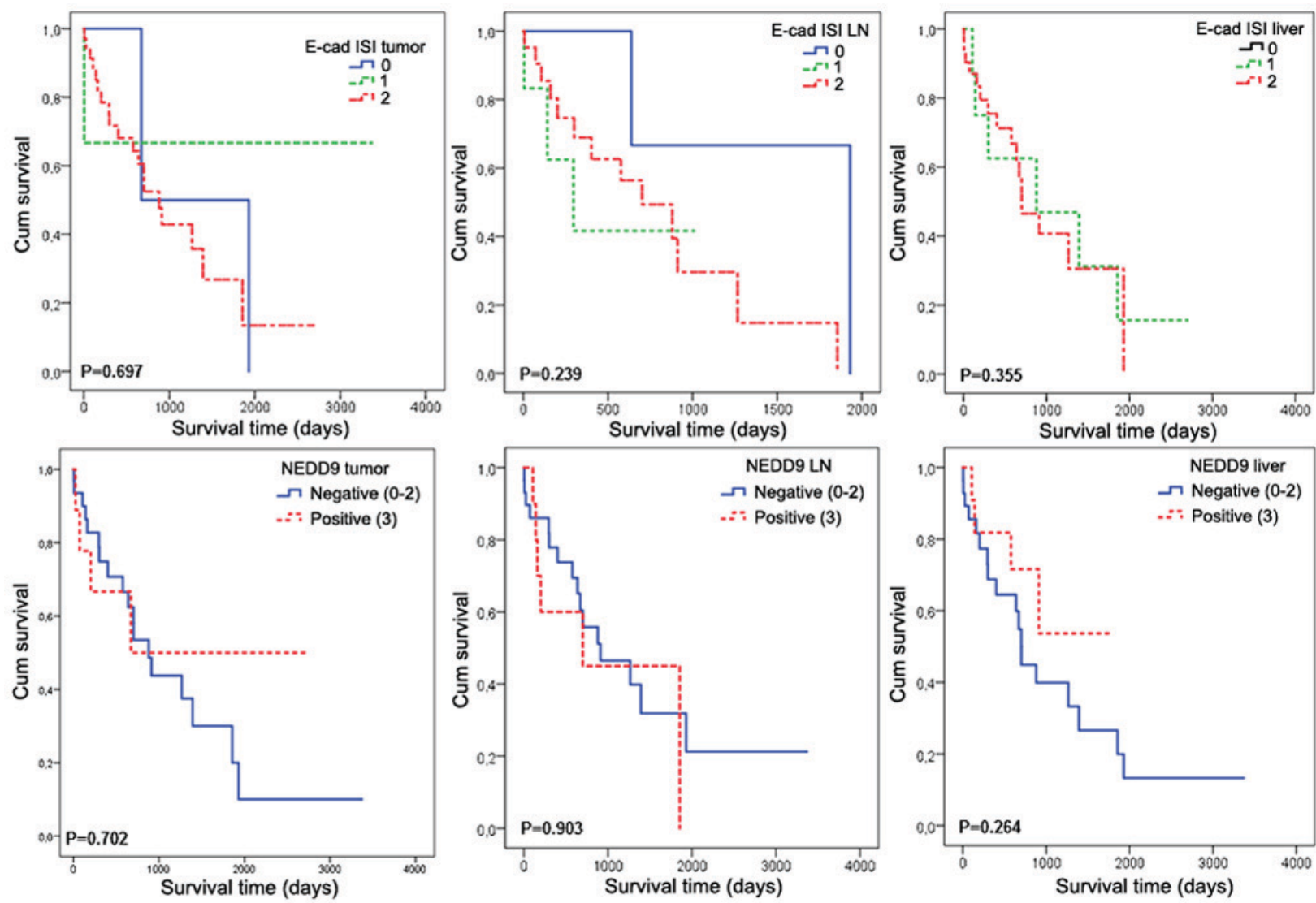

Figure 2. Expression of E-cadherin and NEDD9 in the primary tumor, metastatic LNs and liver metastasis compared with the survival outcome, as demonstrated by Kaplan-Meier survival curves with P-values from the log-rank test. E-cad, E-cadherin; ISI, immunohistochemical staining index; LN, lymph node, NEDD9, neuronal precursor cell-expressed developmentally downregulated 9.

The present study identified a strong expression of NEDD9 in $22.5 \%$ of primary CRC tumors, $35.5 \%$ of LNs and $30 \%$ of liver metastases. As did $\mathrm{Li}$ et al (48), we found a significant positive correlation between positive LN and NEDD9 expression. The difference in the expression of NEDD9 was also noted in cell lines (primary cell line SW480, and LN metastatic cell line SW620, derived from the same patient) (49). To the best of our knowledge, there are no published data on the expression of NEDD9 in CRC liver metastasis. The expression is similar to that of LN. Further studies of the expression of NEDD9 in liver metastases are needed. Potentially due to the small study cohort, no connection between the expression of NEDD9 in the primary tumor, LNs or liver metastases with survival rate was identified in the present study. Limitations of our study mostly arise from the small sample size. However, the registry of Croatian patients that had a resection of their CRC does not exist. Furthermore, there are no universally accepted guidelines for the treatment of CRC, i.e., a similar case will be treated rather differently in various institutions. This situation poses unsurmountable challenges for the accruement of a larger Dukes D patients' group. Since 2014, the EGFR testing has become a standard part of pathological reports. If we were performing the research now, we would include the results of EGFR as a factor determining the sampling of our groups. Clinical significance/relevance lies in the possibility of an improved distinction among patients who will experience more benefits of anti-EGFR therapy. Similar studies about the expression of E-cadherin and benefit of anti-EGFR therapy were published in settings of patients with lung adenocarcinoma $(50,51)$. However, the patients included from 2014 still would not have a sufficient follow-up data at this point. Due to our objectively limited resources and the impossibility to use CEA-controlled oncolytic adenovirus (it is not available in Croatia), CEA was not used, although we recognize it as 'one of the most important factors'. Additional limitations to our study arise from the absence of data on E-cadherin and NEDD9 expression in CRC cell lines and animal models of CRC. In the future diagnostic procedures, if the equipment, samples, and experienced, professional staff would be provided to our institution, we intend to use this method (52).

\section{Acknowledgements}

The authors would like to thank Mrs. Smole from the Clinical Hospital Center Sestre Milosrdnice institutional library, for helping us obtain the necessary references, which would not have otherwise been available to us.

\section{Funding}

No funding was received.

\section{Availability of data and materials}

The datasets used and analyzed during the current study are available from the corresponding author on reasonable request. 


\section{Authors' contributions}

PJ designed and performed the research, wrote the manuscript and analyzed the clinical data. PR and MPB collected and analyzed the samples. MM performed the statistical analysis. BK contributed to the design of the research, supervised the experiments and wrote the manuscript.

\section{Ethics approval and consent to participate}

All of the samples were collected at the time of diagnosis and after obtaining written informed consent. All experiments were performed in accordance with the Declaration of Helsinki and were approved by the Ethics Committee of Clinical Hospital Center Sestre Milosrdnice.

\section{Patient consent for publication}

The patients provided written informed consent for the publication of any associated data and accompanying images.

\section{Competing interests}

The authors declare that they have no competing interests.

\section{References}

1. Croatian National Cancer Registry: Cancer incidence in Croatia 2015. Bulletin No. 40. Zagreb, Croatian National Institute of Public Health, 2018.

2. Balmaňa J, Balanguer F, Cervantes A and Arnold D: Familial risk-colorectal cancer: ESMO clinical practice guidelines. Ann Oncol 24 (Suppl 6): vi73-vi80, 2013

3. Tikhmyanova N and Golemis EA: NEDD9 and BCAR1 negatively regulate E-cadherin membrane localization, and promote E-cadherin degradation. PLoS One 6: e22102, 2011.

4. Huntsman DG and Caldas C: Assignment of the E-cadherin gene (CDH1) to chromosome $16 \mathrm{q} 22.1$ by radiation hybrid mapping. Cytogenet Cell Genet 83: 82-83, 1998 .

5. Fleming TP, Javed Q and Hay M: Epithelial differentiation and intercellular junction formation in the mouse early embryo. Dev Suppl: 105-112, 1992.

6. Paschos KA, Canovas D and Bird NC: The role of cell adhesion molecules in the progression of colorectal cancer and the development of liver metastasis. Cell Signal 21: 665-674, 2009.

7. El-Bahrawy MA, Poulsom R, Jeffery R, Talbot I and Alison MR: The expression of E-cadherin and catenins in sporadic colorectal carcinoma. Hum Pathol 32: 1216-1224, 2001.

8. Pećina-Slaus N: Tumor suppressor gene E-cadherin and its role in normal and malignant cells. Cancer Cell Int 3: 17, 2003.

9. Tikhmyanova N, Little JL and Golemis EA: CAS proteins in normal and pathological cell growth control. Cell Mol Life Sci 67: 1025-1048, 2010.

10. Kong C, Wang C, Wang L, Ma M, Niu C, Sun X, Du J, Dong Z, Zhu S, Lu J and Huang B: NEDD9 is a positive regulator of epithelial-mesenchymal transition and promotes invasion in aggressive breast cancer. PLoS One 6: e22666, 2011.

11. Stajduhar E, Sedić M, Leniček T, Radulović P, Kerenji A, Krušlin B, Pavelić K and Kraljević Pavelić A: Expression of growth hormone receptor, plakoglobin and NEDD9 protein in association with tumour progression and metastasis in human breast cancer. Tumor Biol 35: 6425-6434, 2014.

12. Zhang SS, Wu LH, Liu Q, Chen KS and Zhang XF: Elevated expression of NEDD9 is associated with metastatic activity in gastric cancer. Onco Targets Ther 8: 633-640, 2015.

13. Chang JX, Gao F, Zhao GQ and Zhang GJ: Expression and clinical significance of NEDD9 in lung tissue. Med Oncol 29: 2654-2660, 2012.

14. Kim M, Gans JD, Nogueira C, Wang A, Paik JH, Feng B, Brennan C, Hahn WC, Cordon-Cardo C, Wagner SN, et al: Comparative oncogenomics identifies NEDD9 as a melanoma metastasis gene. Cell 125: 1269-1281, 2006.
15. Wang H, Mu X, Zhou S, Zhang J, Dai J, Tang L, Xiao L, Duan Z, Jia L and Chen S: NEDD9 overexpression is associated with the progression of and an unfavorable prognosis in epithelial ovarian cancer. Hum Pathol 45: 401-408, 2014.

16. Wang Z, Shen M, Lu P, Li X, Zhu S and Yue S: NEDD9 may regulate hepatocellular carcinoma cell metastasis by promoting epithelial-mesenchymal-transition and stemness via repressing Smad7. Oncotarget 8: 1714-1724, 2017.

17. Xue YZ, Sheng YY, Liu ZL, Wei ZQ, Cao HY, Wu YM, Lu YF, Yu LH, Li JP and Li ZS: Expression of NEDD9 in pancreatic ductal adenocarcinoma and its clinical significance. Tumour Biol 34: 895-899, 2013.

18. Morimoto K, Tanaka T, Nitta Y, Ohnishi K, Kawashima H and Nakatani T: NEDD 9 crucially regulates TGF- $\beta$-triggered epithelial-mesenchymal transition and cell invasion in prostate cancer cells: Involvement in cancer progressiveness. Prostate 74: 901-910, 2014.

19. Wang J, Wang S, Luan Y, Zhang W, Sun C, Cheng G, Li K, Xin Q, Lin Z, Qi T and Kong F: Overexpression of NEDD9 in renal cell carcinoma is associated with tumor migration and invasion. Oncol Lett 14: 8021-8027, 2017.

20. Cui X, Shen K, Xie Z, Liu T and Zhang H: Identification of key genes in colorectal cancer using random walk with restart. Mol Med Rep 15: 867-872, 2017.

21. Hong SM, Li A, Olino K, Wolfgang CL, Herman JM, Schulick RD, Iacobuzio-Donahue C, Hruban RH and Goggins M: Loss of E-cadherin expression and outcome among patients with resectable pancreatic adenocarcinomas. Mod Pathol 24: 1237-1247, 2011.

22. Yun JA, Kim SH, Hong HK, Yun SH, Kim HC, Chun HK, Cho YB and Lee WY: Loss of E-Cadherin expression is associated with a poor prognosis in stage III colorectal cancer. Oncology 86: 318-328, 2014.

23. Dorudi S, Sheffield JP, Poulsom R, Northover JM and Hart IR: E-cadherin expression in colorectal cancer. An immunocytochemical and in situ hybridization study. Am J Pathol 142: 981-986, 1993

24. Miladi-Abdennadher I, Abdelmaksoud-Dammak R, Ayed-Guerfali DB, Ayadi L, Khabir A, Amouri A, Frikha F, Tahri N, Ellouz S, Frikha M, et al: Expression of COX-2 and E-cadherin in Tunisian patients with colorectal adenocarcinoma. Acta Histochem 114: 577-581, 2012.

25. Palaghia M, Mihai C, Lozneanu L, Ciobanu D, Trofin AM, Rotariu A, Târcoveanu F and Cijevschi Prelipcean C: E-cadherin expression in primary colorectal cancer and metastatic lymph nodes. Rom J Morphol Embryol 57: 205-209, 2016.

26. Elzagheid A, Buhmeida A, Laato M, El-Faitori O, Syrjänen K, Collan Y and Pyrhönen S: Loss of E-cadherin expression predicts disease recurrence and shorter survival in colorectal carcinoma. APMIS 120: 539-548, 2012.

27. Gu J, Zhu X, Ye Y, Qu J, Huang L, Li R, Yu Y and Leng X: The level of expression of adhesion molecules CD44v6 and E-cadherin in colorectal cancer and analysis of correlates with metastasis. Zhonghua Wai Ke Za Zhi 37: 108-109, 4, 1999 (In Chinese).

28. Elzagheid A, Algars A, Bendardaf R, Lamlum H, Ristamaki R, Collan Y, Syrjanen K and Pyrhonen S: E-cadherin expression pattern in primary colorectal carcinomas and their metastases reflects disease outcome. World J Gastroenterol 12: 4304-4309, 2006.

29. Tóth L, András C, Molnár C, Tanyi M, Csiki Z, Molnár P and Szántó J: Investigation of $\beta$-catenin and E-cadherin expression in Dukes B2 stage colorectal cancer with tissue microarray method. Is it a marker of metastatic potential in rectal cancer? Pathol Oncol Res 18: 429-437, 2012.

30. Khoursheed MA, Mathew TC, Makar RR, Louis S, Asfar SK, Al-Sayer HM, Dashti HM and Al-Bader A: Expression of E-cadherin in human colorectal cancer. Surgeon 1: 86-91, 2003.

31. Roca F, Mauro LV, Morandi A, Bonadeo F, Vaccaro C, Quintana GO, Specterman S, de Kier Joffé EB, Pallotta MG, Puricelli LI and Lastiri J: Prognostic value of E-cadherin, beta-catenin, MMPs ( 7 and 9), and TIMPs ( 1 and 2 ) in patients with colorectal carcinoma. J Surg Oncol 93: 151-160, 2006.

32. Ghadimi BM, Behrens J, Hoffmann I, Haensch W, Birchmeier W and Schlag PM: Immunohistological analysis of E-cadherin, alpha-, beta- and gamma-catenin expression in colorectal cancer: Implications for cell adhesion and signaling. Eur J Cancer 35: 60-65, 1999. 
33. Kwak JM, Min BW, Lee JH, Choi JS, Lee SI, Park SS, Kim J, Um JW, Kim SH and Moon HY: The prognostic significance of E-cadherin and liver intestine-cadherin expression in colorectal cancer. Dis Colon Rectum 50: 1873-1880, 2007.

34. Lugli A, Zlobec I, Minoo P, Baker K, Tornillo L, Terracciano L and Jass JR: Prognostic significance of the wnt signalling pathway molecules APC, beta-catenin and E-cadherin in colorectal cancer: A tissue microarray-based analysis. Histopathology 50: 453-464, 2007.

35. Karamitopoulou E, Zlobec I, Patsouris E, Peros G and Lugli A: Loss of E-cadherin independently predicts the lymph node status in colorectal cancer. Pathology 43: 133-137, 2011.

36. Ozgüven BY, Karaçetin D, Kabukçuoğlu F, Taşkin T and Yener S: Immunohistochemical study of E-cadherin and $\beta$-catenin expression in colorectal carcinomas. Pol J Pathol 62: 19-24, 2011.

37. Kim SA, Inamura K, Yamauchi M, Nishihara R, Mima K, Sukawa Y, Li T, Yasunari M, Morikawa T, Fitzgerald KC, et al: Loss of CDH1 (E-cadherin) expression is associated with infiltrative tumour growth and lymph node metastasis. Br J Cancer 114: 199-206, 2016

38. Ikeguchi M, Taniguchi T, Makino $M$ and Kaibara N: Reduced E-cadherin expression and enlargement of cancer nuclei strongly correlate with hematogenic metastasis in colorectal adenocarcinoma. Scand J Gastroenterol 35: 839-846, 2000.

39. Kim JC, Roh SA, Kim HC, Koo KH, Cho YK, Yu CS, Kwon YM and Kim JS: Coexpression of carcinoembryonic antigen and E-cadherin in colorectal adenocarcinoma with liver metastasis. J Gastrointest Surg 7: 931-938, 2003.

40. Mohri Y: Prognostic significance of E-cadherin expression in human colorectal cancer tissue. Surg Today 27: 606-612, 1997.

41. Nanashima A, Yamaguchi H, Sawai T, Yamaguchi E, Kidogawa H, Matsuo S, Yasutake T, Tsuji T, Jibiki M, Nakagoe T and Ayabe H: Prognostic factors in hepatic metastases of colorectal carcinoma: Immunohistochemical analysis of tumor biological factors. Dig Dis Sci 46: 1623-1628, 2001 .

42. Kaihara T, Kusaka T, Nishi M, Kawamata H, Imura J, Kitajima K, Itoh-Minami R, Aoyama N, Kasuga M, Oda Y, et al: Dedifferentiation and decreased expression of adhesion molecules, E-cadherin and ZO-1, in colorectal cancer are closely related to liver metastasis. J Exp Clin Cancer Res 22: 117-123, 2003.

43. Truant SC, Gouyer VP, Leteurtre EA, Zerimech F, Huet GM and Pruvot FR: E-cadherin and beta-catenin mRNA levels throughout colon cancer progression. J Surg Res 150: 212-218, 2008.

44. Gagliardi G, Kandemir O, Liu D, Guida M, Benvestito S, Ruers TG, Benjamin IS, Northover JM, Stamp GW Talbot IC, et al: Changes in E-cadherin immunoreactivity in the adenoma-carcinoma sequence of the large bowel. Virchows Arch 426: 149-154, 1995
45. Kang H, Min BS, Lee KY, Kim NK, Kim SN, Choi J and Kim H: Loss of E-cadherin and MUC2 expressions correlated with poor survival in patients with stages II and III colorectal carcinoma. Ann Surg Oncol 18: 711-719, 2011.

46. Lee SJ, Choi SY, Kim WJ, Ji M, Lee TG, Son BR, Yoon SM, Sung R, Lee EJ, Youn SJ and Park SM: Combined aberrant expression of E-cadherin and S100A4, but not $\beta$-catenin is associated with disease-free survival and overall survival in colorectal cancer patients. Diagn Pathol 8: 99, 2013.

47. Xia D, Holla VR, Wang D, Menter DG and DuBois RN: HEF1 is a crucial mediator of the proliferative effects of prostaglandin E(2) on colon cancer cells. Cancer Res 70: 824-831, 2010.

48. Li P, Zhou H, Zhu X, Ma G, Liu C, Lin B and Mao W: High expression of NEDD9 predicts adverse outcomes of colorectal cancer patients. Int J Clin Exp Pathol 7: 2565-2570, 2014

49. Li Y, Bavarva JH, Wang Z, Guo J, Qian C, Thibodeau SN, Golemis EA and Liu W: HEF1, a novel target of Wnt signaling, promotes colonic cell migration and cancer progression. Oncogene 30: 2633-2643, 2011.

50. Awasthi S, Maity T, Oyler BL, Qi Y, Zhang X, Goodlett DR and Guha U: Quantitative targeted proteomic analysis of potential markers of tyrosine kinase inhibitor (TKI) sensitivity in EGFR mutated lung adenocarcinoma. J Proteomics 189: 48-59, 2018.

51. Miao Y, Li AL, Wang L, Fan CF, Zhang XP, Xu HT, Yang LH, Liu $Y$ and Wang EH: Overexpression of NEDD9 is associated with altered expression of E-Cadherin, $\beta$-Catenin and $\mathrm{N}$-Cadherin and predictive of poor prognosis in non-small cell lung cancer. Pathol Oncol Res 19: 281-286, 2013.

52. Zhang R, Zhang X, Ma B, Xiao B, Huang F, Huang P, Ying C, Liu T and Wang Y: Enhanced antitumor effect of combining TRAIL and MnSOD mediated by CEA-controlled oncolytic adenovirus in lung cancer. Cancer Gene Ther 23: 168-177, 2016.

This work is licensed under a Creative Commons Attribution-NonCommercial-NoDerivatives 4.0 International (CC BY-NC-ND 4.0) License. 